Check for updates

Cite this: RSC Adv., 2019, 9, 15561

Received 27th February 2019

Accepted 23rd April 2019

DOI: 10.1039/c9ra01486a

rsc.li/rsc-advances

\section{Alkylammonium thiostannate inorganic/organic hybrids as high-performance photocatalysts with a decoupled adsorption-photodegradation mechanism $\uparrow$}

\author{
Xiufang Hao, ${ }^{a}$ Xiaoyan Cui, ${ }^{a}$ Meiqi $\mathrm{Hu}^{a}{ }^{a}$ Yiming $\mathrm{Jia}{ }^{a}$ Xinxin $\mathrm{Li}^{\mathrm{b}}{ }^{\mathrm{b}}$ Shuo Wei (D) *a \\ and Jun Lu (D) ${ }^{c}$
}

For traditional photocatalysts, the adsorption and successive surface reaction constitute a coupled and integrated process, owing to the limited number of catalytic active centres available. An attempt to boost the photocatalytic performance to optimize the adsorption and surface reaction process may be performed by exploring various photocatalyst infrastructures. Herein, we use a facile solvothermal method to synthesize a series of layered alkylammonium thiostannate hybrids, namely $(\text { baH })_{2} \mathrm{Sn}_{3} \mathrm{~S}_{7}$, $(\mathrm{haH})_{2} \mathrm{Sn}_{3} \mathrm{~S}_{7}$ and $(\mathrm{oaH})_{2} \mathrm{Sn}_{3} \mathrm{~S}_{7}$ (ba = butylamine, ha = hexylamine, oa = octylamine). The hybrids showed broad UV-visible light absorption with appropriate band gaps. The inorganic/organic amphiphilic infrastructure of these hybrids enables them to exhibit prominent ion-exchange properties for Rhodamine $\mathrm{B}$, with a large capacity over a wide $\mathrm{pH}$ range (1-11). And the adsorbed Rhodamine $\mathrm{B}$ is photodegraded within 30 minutes. A mechanistic study indicates that the adsorption and photodegradation steps are performed at the organic and inorganic layers within these hybrids, respectively, which are decoupled and independent. We conclude that the high-performance integrated adsorption-photodegradation ability is a consequence of the lipophilicity of intercalated alkylammonium and the photocatalysis performance of the $2 \mathrm{D}\left[\mathrm{Sn}_{3} \mathrm{~S}_{7}\right]_{n}^{2 n-}$ monolayers.

\section{Introduction}

Inorganic-organic hybrid chalcogenides have attracted considerable interest, where the organic components and inorganic motifs are bonded by ionic bonds, covalent bonds, hydrogen bonds or van der Waals forces to form chalcogenide-based open-framework structures, and exhibit different optical, electrical and magnetic properties from their bulk counterparts. ${ }^{1}$ Among these hybrids, II-VI transition metal chalcogenides are especially important. Their periodic structure enables them to display a strong quantum confinement effect, for example, $\alpha$ ZnTe(en) $)_{1 / 2}, \beta-Z n T e(e n)_{1 / 2}$, and ZnTe(pda) $)_{1 / 2}$ (en = ethylenediamine, pda $=$ propanediamine) exhibit a large blue shift (1.2$1.4 \mathrm{eV}$ ) of the absorption edge compared with bulk ZnTe. ${ }^{2}$ In addition, the amine-hybrid chalcogenides can act as

${ }^{a}$ College of Chemistry, Beijing Normal University, Beijing 100875, PR China. E-mail: vshuo@bnu.edu.cn

${ }^{b}$ Analytical and Testing Center, Beijing Normal University, Beijing 100875, PR China ${ }^{c}$ State Key Laboratory of Chemical Technology, Beijing University of Chemical Technology, Beijing 100875, PR China

$\dagger$ Electronic supplementary information (ESI) available: The full elements analyses, XPS, TGA of $\mathrm{A}_{2} \mathrm{Sn}_{3} \mathrm{~S}_{7}$, comparison of the adsorption capacities on various adsorbents for RhB. PXRD of $(\mathrm{baH})_{2} \mathrm{Sn}_{3} \mathrm{~S}_{7}$ catalyst in cycle process. See DOI: $10.1039 / \mathrm{c} 9 \mathrm{ra} 01486 \mathrm{a}$ intermediates to prepare ultrathin nanosheets, such as the reported large-area [ZnSe] monolayers with a four-atom-layer thickness that are stripped from the lamellar $\left(\mathrm{Zn}_{2} \mathrm{Se}_{2}\right)(\mathrm{pa})$ intermediate ( $\mathrm{pa}=n$-propylamine). It has been proved that the prepared ZnSe monolayer exhibits a unique electronic structure, excellent stability, enhanced photocatalytic water splitting efficiency and photostability. ${ }^{3}$ Similarly, the ultrathin $\mathrm{Zn}_{1-x^{-}}$ $\mathrm{Cd}_{x} \mathrm{~S}$ nanosheets with atomic-scale thickness, prepared by liquid exfoliation of lamellar $\mathrm{Zn}_{1-x} \mathrm{Cd}_{x} \mathrm{~S}$ (ha) (ha = hexylamine) complexes, were the first transferable two-dimensional (2D) white light-emitter obtained by engineering grain boundaries in atomically-thin semiconducting nanosheets. ${ }^{4}$

The pioneering work of R. L. Bedard demonstrated the synthesis of microporous germanium and the tin sulphide phase by a hydrothermal method in the presence of alkylammonium cations. ${ }^{5}$ Since then, the application of amines for the synthesis of chalcogenidometalates of group 13-15 elements by a solvothermal method has thrived, such as germanium, tin, arsenic, antimony, and indium chalcogenides. These compounds not only possess the ion exchange and catalysis properties, which are characteristic of microporous oxides, but also inherit the semiconductor properties of chalcogenides. ${ }^{6}$ The basic structural units of germanium and tinsulphur compounds are $\mathrm{MQ}_{4}(\mathrm{M}=\mathrm{Ge}, \mathrm{Sn} ; \mathrm{Q}=\mathrm{S}$, Se, and Te $)$ 
tetrahedra, and multiple $\mathrm{MQ}_{4}$ tetrahedra are shared by corners or edges to form secondary structural units such as polytetrahedra $\left[\mathrm{M}_{2} \mathrm{Q}_{6}\right]^{4-},\left[\mathrm{M}_{3} \mathrm{Q}_{7}\right]^{2-},\left[\mathrm{M}_{4} \mathrm{Q}_{9}\right]^{2-}$, and $\left[\mathrm{M}_{4} \mathrm{Q}_{10}\right]^{4-}$. These secondary structural units form inorganic-organic hybrid chalcogenides in different structures of $0-3$ dimensions by supramolecular assembly or polymerization. ${ }^{7}$ G. A. Ozin et al. focused on synthesizing a series of $\mathrm{R}_{2} \mathrm{Sn}_{3} \mathrm{~S}_{7}$ (R-SnS-1, $\mathrm{Me}_{4} \mathrm{~N}^{+}$, $\left.\mathrm{Et}_{4} \mathrm{~N}^{+}, \mathrm{QUIH}^{+}, \mathrm{DABCOH}^{+}\right)$and $\mathrm{R}_{2} \mathrm{Sn}_{4} \mathrm{~S}_{9}\left(\mathrm{R}=\mathrm{Pr}_{3} \mathrm{NH}^{+}, \mathrm{BuNH}_{3}{ }^{+}\right)$ type compounds, where the organic cations existed in the pores and/or the interlamellar spacing. ${ }^{8}$ Furthermore, layered $\mathrm{A}_{2} \mathrm{Sn}_{3} \mathrm{~S}_{7}$ ( $\mathrm{A}=$ cations) hybrids can be used as a novel kind of ion exchanger to remove heavy metal ions, ${ }^{9-11}$ which could effectively avoid the instability of the organic ion exchanger in aqueous solution and the $\mathrm{pH}$ sensitivity of the inorganic ion exchanger. ${ }^{12}$ Some hybrid ion exchangers have been reported, such as $\left[\left(\mathrm{CH}_{3} \mathrm{CH}_{2} \mathrm{CH}_{2}\right)_{2} \mathrm{NH}_{2}\right]_{5} \mathrm{In}_{5} \mathrm{Sb}_{6} \mathrm{~S}_{19} \cdot 1.45 \mathrm{H}_{2} \mathrm{O},{ }^{13}$ $\left[\left(\mathrm{CH}_{3}\right)_{2} \mathrm{NH}_{2}\right]_{2} \mathrm{Ga}_{2} \mathrm{Sb}_{2} \mathrm{~S}_{7} \cdot \mathrm{H}_{2} \mathrm{O},{ }^{14} \quad\left[\left(\mathrm{CH}_{3}\right)_{2} \mathrm{NH}_{2}\right]_{2}\left[\mathrm{GeSb}_{2} \mathrm{~S}_{6}\right],{ }^{15}$ and $\left[\left(\mathrm{CH}_{3}\right)_{2} \mathrm{NH}_{2}\right]_{0.75}\left[\mathrm{Ag}_{1.25} \mathrm{SnSe}_{3}\right]{ }^{16}$ Recently, Huang et al. successfully synthesized a new thiostannate $\left[\mathrm{Me}_{2} \mathrm{NH}_{2}\right]_{4 / 3}\left[\mathrm{Me}_{3} \mathrm{NH}\right]_{2 / 3}$ $\mathrm{Sn}_{3} \mathrm{~S}_{7} \cdot 1.25 \mathrm{H}_{2} \mathrm{O}$ (denoted as FJSM-SnS) to adsorb $\mathrm{Cs}^{+}$and $\mathrm{Sr}^{2+}$, $\mathrm{UO}_{2}{ }^{+},{ }^{10}$ and rare-earth elements. ${ }^{11}$ FJSM-SnS possesses a microporous layered structure with $2 \mathrm{D}\left[\mathrm{Sn}_{3} \mathrm{~S}_{7}\right]_{n}{ }^{2 n-}$ layers stacked in AA sequence along the $c$-axis, and alkylammonium as counter cations existing in the interlayers. It has been revealed that FJSM-SnS, as a superior ion-exchanger, exhibits a high exchange rate, high adsorption capacity and wide $\mathrm{pH}$ resistance during the ion-exchange process. Compared with inorganic ionexchangers having $\mathrm{K}^{+}$and $\mathrm{NH}_{4}{ }^{+}$as counterions, ${ }^{17-19}$ the alkylammonium chalcogenides with tunable size and conformationally flexible alkylammonium are promising ion-exchangers.

Photocatalysis is a thorough and eco-friendly approach for the degradation of toxic, carcinogenic and non-biodegradable pollutants. A highly efficient photocatalyst is required to have a broad photoresponse, effective separation of the photogenerated electrons and holes, and prominent adsorption capacity for reactants. To date, some inorganic chalcogenides, such as $\mathrm{CdS},{ }^{20} \mathrm{SnS}_{2},{ }^{21} \mathrm{Bi}_{2} \mathrm{~S}_{3},{ }^{22} \mathrm{MoS}_{2},{ }^{23}$ and $\mathrm{ZnIn}_{2} \mathrm{~S}_{4},{ }^{24}$ have been developed as visible-light photocatalysts owing to their tunable band gaps and promising photocatalytic potential. However, the limited adsorption capacity seriously prevents their high performance photocatalysis, ${ }^{25-27}$ which is a notorious and tough problem that hampers performance improvement. Especially in the treatment of water-soluble organic pollutants, inorganic photocatalysts cannot effectively adsorb hydrophobic contaminants, which degrades the photocatalytic efficiency to some extent. Therefore, pre-adsorption is a prerequisite for efficient photocatalysis. $^{28}$ Based on the excellent adsorption performance of layered $\mathrm{A}_{2} \mathrm{Sn}_{3} \mathrm{~S}_{7}$ on the capture of heavy metal ions, it was proposed that the oleophilic group of interlayered alkylammonium could have a positive effect on the adsorption of organic pollutants. Meanwhile, it has been reported that organic cationic dyes, such as Methylene Blue (MB) or Safranin $\mathrm{T}$ (ST), have been introduced into the crystalline structure of $2 \mathrm{D}$ thiostannate $(\operatorname{trenH})_{2} \mathrm{Sn}_{3} \mathrm{~S}_{7}$ (tren $=\operatorname{tris}(2$-aminoethyl)amine) by ion exchange with an adsorption capacity of $45 \mathrm{mg} \mathrm{g}^{-1} \cdot{ }^{29}$ This revealed that the oleophility of the interlayered alkylammonium would be favourable to enhance the adsorption of organic contaminants and, replacing shorter chain alkylammonium with longer chain alkylammonium in the hybrid should be reasonable to enhance this adsorption. Furthermore, if the hybrid possesses an ion-exchange and photocatalytic ability at the same time, the organic pollutants could be further thoroughly degraded in an environmental-friendly way. These hybrids that combine a high adsorption capacity with excellent photocatalytic ability would be a new concept photocatalyst with a distinctive photocatalytic mechanism. However, to date, there are only a few studies that have focused on investigating alkylammonium thiostannate hybrids as high performance photocatalysts.

Herein, we synthesized a series of layered thiostannates, namely (baH) $)_{2} \mathrm{Sn}_{3} \mathrm{~S}_{7}$ (ba = butylamine), $(\mathrm{haH})_{2} \mathrm{Sn}_{3} \mathrm{~S}_{7}$ (ha = hexylamine) and (oaH $)_{2} \mathrm{Sn}_{3} \mathrm{~S}_{7}$ (oa = octylamine), which are denoted as $\mathrm{A}_{2} \mathrm{Sn}_{3} \mathrm{~S}_{7}(\mathrm{~A}=\mathrm{baH}, \mathrm{haH}, \mathrm{oaH})$, by a facile, one-pot solvothermal method. Using the organic cation dye Rhodamine $\mathrm{B}(\mathrm{RhB})$ as a prototypical pollutant, the ion-exchange and photocatalytic properties of $\mathrm{A}_{2} \mathrm{Sn}_{3} \mathrm{~S}_{7}(\mathrm{~A}=\mathrm{baH}, \mathrm{haH}, \mathrm{oaH})$ were explored. The results indicated that the three thiostannates could quickly adsorb $\mathrm{RhB}$ through the ion-exchange reaction with enormous exchange capacities of $1047 \mathrm{mg} \mathrm{g}^{-1}$ to $1305 \mathrm{mg}$ $\mathrm{g}^{-1}$. In addition, $\mathrm{A}_{2} \mathrm{Sn}_{3} \mathrm{~S}_{7}$ could maintain their robust layered framework and effective photoabsorption over a wide $\mathrm{pH}$ range (1-11) during the ion-exchange processes. More importantly, $\mathrm{A}_{2} \mathrm{Sn}_{3} \mathrm{~S}_{7}$ showed an excellent photodegradation ability for the adsorbed RhB within 15-60 min with a remarkable recycle stability, which demonstrated that $\mathrm{A}_{2} \mathrm{Sn}_{3} \mathrm{~S}_{7}$ is a novel highperformance photocatalyst with a decoupled adsorption and photocatalysis mechanism, based on its inorganic-organic layered structure.

\section{Experimental}

\subsection{Material synthesis}

All reagents and chemicals were purchased from commercial sources and used without further purification. For the synthesis of $(\mathrm{baH})_{2} \mathrm{Sn}_{3} \mathrm{~S}_{7}$ : a mixture of $\mathrm{SnCl}_{4} \cdot 5 \mathrm{H}_{2} \mathrm{O}(8 \mathrm{mmol}, 2.806 \mathrm{~g}), \mathrm{S}$ $(32 \mathrm{mmol}, 1.026 \mathrm{~g})$ in butylamine $(12 \mathrm{~mL})$ and water $(4 \mathrm{~mL})$ was stirred under ambient conditions until homogeneously mixed. The resulting mixture was sealed in a $50 \mathrm{~mL}$ stainless steel reactor with a Teflon liner, heated at $180^{\circ} \mathrm{C}$ for $12 \mathrm{~h}$ and then cooled to room temperature. The final products were obtained by centrifugation, then washed with ethanol and vacuum dried. The synthesis procedures for $(\mathrm{haH})_{2} \mathrm{Sn}_{3} \mathrm{~S}_{7}$ and $(\mathrm{oaH})_{2} \mathrm{Sn}_{3} \mathrm{~S}_{7}$ were similar as $(\mathrm{baH})_{2} \mathrm{Sn}_{3} \mathrm{~S}_{7}$, except for the solvents used were hexylamine and octylamine, and the reaction time was 3 days and 5 days, respectively.

\subsection{Characterization}

Powder X-ray diffraction (PXRD) patterns were obtained on a PANalytical X Pert PRO MPD X-ray Powder Diffractometer working at $40 \mathrm{kV}$ and $40 \mathrm{~mA}$ using $\mathrm{Cu} \mathrm{K} \alpha$ radiation (1.541844 $\mathrm{A}$ ) in the angular range of $2 \theta=3.5-60^{\circ}$ at room temperature. Elemental analyses of $\mathrm{C}, \mathrm{H}$ and $\mathrm{N}$ were carried out with a German Elementary Vario EL instrument. Inductively coupled 
plasma (ICP) atomic emission spectral analyses were performed with a SPECTRO axial-view inductively coupled plasma spectrometer. The morphology of the products was characterized by a Hitachi S-8010 field emission scanning electron microscope. X-ray photoelectron spectroscopy (XPS) measurements were conducted on an ESCALAB 250Xi X-ray photoelectron spectrometer with a $\mathrm{Mg}$ target $(1283 \mathrm{eV})$. The thermogravimetric (TG) analyses were performed on a Mietler Toledo TGA/DSC thermogravimetric analyser with a $5{ }^{\circ} \mathrm{C} \mathrm{min}^{-1}$ ramp from 25 to $700{ }^{\circ} \mathrm{C}$ in $\mathrm{N}_{2}$ gas. UV-visible (UV-Vis) diffuse reflection spectra were obtained with a PerkinElmer Lambda $950 \mathrm{UV} / \mathrm{VIS} / \mathrm{NIR}$ spectrometer by using $\mathrm{BaSO}_{4}$ as a standard (100\% reflectance) at room temperature. The UV-Vis absorption spectra were collected in the range from 300 to $700 \mathrm{~nm}$ on a Shimadzu UV2600 spectrophotometer with the slit width of $1.0 \mathrm{~nm}$. The steady state fluorescence excitation and emission spectra were performed on an Edinburgh-FS5 fluorescence spectrophotometer with the excitation and emission slit widths of $3.0 \mathrm{~nm}$.

\subsection{Ion-exchange experiments}

Isotherm adsorption. A set of RhB solutions with a concentration ranging from 20 to $450 \mathrm{mg} \mathrm{L}^{-1}$ were prepared beforehand. $\mathrm{A}_{2} \mathrm{Sn}_{3} \mathrm{~S}_{7}$ samples (30 mg) were added into $\mathrm{RhB}$ solutions $(100 \mathrm{~mL})$ at $333 \mathrm{~K}$ in an incubator shaker in the dark. Until equilibrium, the concentration of RhB was determined by UVVis absorption spectroscopy. Appropriate dilution was conducted, if necessary.

Adsorption kinetics. $\mathrm{A}_{2} \mathrm{Sn}_{3} \mathrm{~S}_{7}$ samples $(30 \mathrm{mg})$ were added into RhB solution $\left(100 \mathrm{~mL} ; 20 \mathrm{mg} \mathrm{L}^{-1}\right)$, then the mixture was shaken in an incubator shaker at $298 \mathrm{~K}$ in the dark. During the experiments, an aliquot of the suspension $(2 \mathrm{~mL})$ was taken from the solution every five minutes, and filtered by a Nylon 66 microporous membrane. Finally, the concentration of the dye solution was determined by UV-Vis absorption spectroscopy at the calibrated maximum wavelength of $554 \mathrm{~nm}$ for RhB.

pH-dependent adsorption tests. RhB aqueous solutions with a pH value ranging from 1 to 11 were prepared by adding $\mathrm{NaOH}$ or $\mathrm{HCl}$ solution. Then the typical ion-exchange experiments were carried out within $30 \mathrm{~min}$. The $\mathrm{A}_{2} \mathrm{Sn}_{3} \mathrm{~S}_{7}$ hybrid load was still $0.3 \mathrm{~g} \mathrm{~L}^{-1}$.

\subsection{Photocatalytic activity tests}

Photocatalysis. The visible-light driven photocatalytic degradation reactions of $\mathrm{RhB}$ were used as probes to evaluate the catalytic performances of $\mathrm{A}_{2} \mathrm{Sn}_{3} \mathrm{~S}_{7}$. All reactions were carried out at $298 \mathrm{~K}$ in a $250 \mathrm{~mL}$ quartz reactor. Prior to the irradiation, RhB solutions $\left(100 \mathrm{~mL} ; 20 \mathrm{mg} \mathrm{L}^{-1}\right)$ containing the $\mathrm{A}_{2} \mathrm{Sn}_{3} \mathrm{~S}_{7}$ samples $(30 \mathrm{mg}$ ) were magnetically stirred in the dark to reach adsorption-desorption equilibrium, then were irradiated by a $300 \mathrm{~W}$ Xenon lamp (CHF-XM300) located $10 \mathrm{~cm}$ away from the suspension. A cutoff filter was equipped to remove UV light below $420 \mathrm{~nm}$.

Photocatalytic kinetics. During the photocatalytic experiments, an aliquot of suspension $(2 \mathrm{~mL})$ was added to a $5 \mathrm{~mL}$ centrifuge tube at regular intervals before adding a mixed extractant $\left(2 \mathrm{~mL} ; \mathrm{v}_{\text {ethanol }}: \mathrm{v}_{\text {dichloromethane }}=3: 1\right)$. After sufficient oscillation and centrifugation, the supernatant was discarded and the remainder was diluted to $2 \mathrm{~mL}$ using the mixed extractant. The RhB concentration was determined by a fluorescence spectrophotometer at the maximum photoluminescence wavelength of $570 \mathrm{~nm}$ for RhB.

Photocatalytic cycle. The photocatalytic reaction system was expand to $300 \mathrm{~mL}$ of $20 \mathrm{mg} \mathrm{L}^{-1}$ of RhB solution with $90 \mathrm{mg}$ of photocatalyst (baH) $)_{2} \mathrm{Sn}_{3} \mathrm{~S}_{7}$. After the first cycle of the photocatalytic reaction, the dispersion solution was firstly centrifuged with high-speed centrifugal $(8000 \mathrm{rpm})$ to discard the supernatant. Due to the hydrophobicity of catalyst, there was small amounts lost. Next, butyl amine was added as eluent to wash photocatalytic product away. Because of its lipophilicity, the photocatalyst could be sufficiently dispersed in organic amine, and settled to the bottom of the centrifuge tube during the highspeed centrifugal sedimentation, which effectively reduced the loss of catalyst during the washing process. After centrifugation, the eluent was discarded and the catalyst was washed with anhydrous ethanol until the $\mathrm{pH}$ value was neutral. After drying, the second cycle experiment was conducted until the fourth cycle experiment.

Adsorption-photocatalytic integration. RhB solutions (100 $\mathrm{mL} ; 20 \mathrm{mg} \mathrm{L}^{-1}$ ) containing $\mathrm{A}_{2} \mathrm{Sn}_{3} \mathrm{~S}_{7}$ samples (30 mg) were irradiated under visible light once magnetically stirred. The filter liquor $(2 \mathrm{~mL})$ was sampled and the $\mathrm{RhB}$ concentration was detected by UV-Vis absorption spectroscopy, immediately.

Photocatalytic mechanism. Ethylene diamine tetraacetic acid (1.0 mM; EDTA) as a quencher of holes, iso-propanol (1.0 $\mathrm{mM}$; IPA) as a quencher of $\cdot \mathrm{OH}$ and $p$-benzoquinone $(1.0 \mathrm{mM} ; \mathrm{BQ})$ as a quencher of $\cdot \mathrm{O}_{2}{ }^{-}$were employed in the photocatalytic process to trap active species of hole, $\cdot \mathrm{OH}$, and $\cdot \mathrm{O}_{2}{ }^{-}$radicals, respectively, for the photocatalytic mechanism investigation.

\section{Results and discussion}

\subsection{Structural characterization}

The XRD patterns of the as-prepared $\mathrm{A}_{2} \mathrm{Sn}_{3} \mathrm{~S}_{7}$ are shown in Fig. 1a. The three thiostannates featured layered structures,
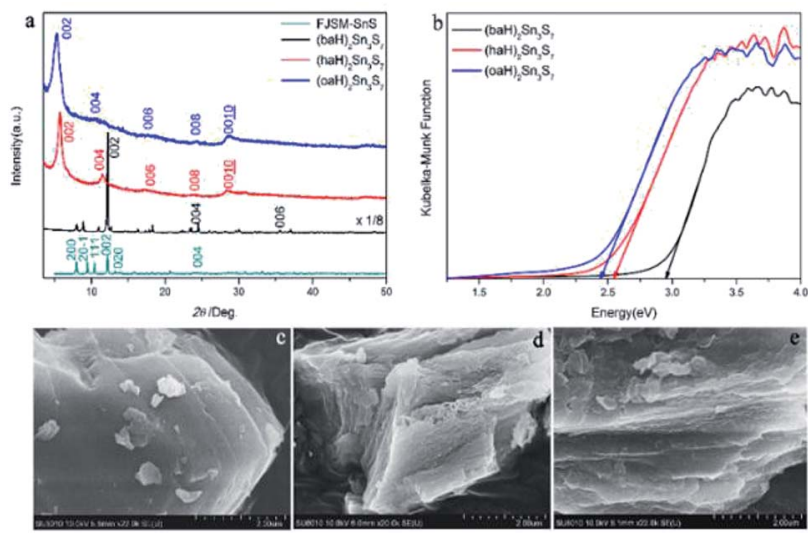

Fig. 1 The PXRD patterns of $\mathrm{A}_{2} \mathrm{Sn}_{3} \mathrm{~S}_{7}$ (a); solid-state optical adsorption spectra (b), SEM patterns of $(\text { baH })_{2} \mathrm{Sn}_{3} \mathrm{~S}_{7}$ (c), $(\mathrm{haH})_{2} \mathrm{Sn}_{3} \mathrm{~S}_{7}$ (d), and $(\mathrm{oaH})_{2} \mathrm{Sn}_{3} \mathrm{~S}_{7}(\mathrm{e})$. 
which presented characteristic $00 l$ diffraction peaks. Using FJSM-SnS as a reference, ${ }^{9}$ the strongest peaks of $(\mathrm{baH})_{2} \mathrm{Sn}_{3} \mathrm{~S}_{7}(2 \theta$ $=12.18^{\circ}, 7.26 \AA$ ) could be assigned to the 002 diffraction, and the other diffraction peaks located at $24.47^{\circ}(3.63 \AA)$ and $37.04^{\circ}$ (2.42 $\AA$ ) corresponded to 004 and 006, respectively. Compared with (baH) $)_{2} \mathrm{Sn}_{3} \mathrm{~S}_{7}$, the diffraction peak intensity of (haH $)_{2} \mathrm{Sn}_{3} \mathrm{~S}_{7}$ and $(\mathrm{oaH})_{2} \mathrm{Sn}_{3} \mathrm{~S}_{7}$ appeared weaker. A series of diffraction peaks located at $2 \theta=5.73^{\circ}(15.41 \AA), 11.54^{\circ}(7.66 \AA), 17.24^{\circ}(5.14 \AA)$, $23.94^{\circ}(3.85 \AA)$, and $28.46^{\circ}(3.13 \AA)$ for $(\mathrm{haH})_{2} \mathrm{Sn}_{3} \mathrm{~S}_{7}$ and $5.29^{\circ}$

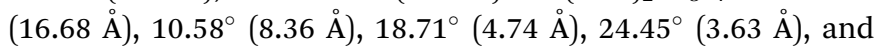
$28.50^{\circ}(3.13 \AA)$ for $(\mathrm{oaH})_{2} \mathrm{Sn}_{3} \mathrm{~S}_{7}$, corresponded to the 002, 004, 006, 008, 0010 diffraction, respectively. These structures were similar to those of the tin sulphides FJMS-SnS, ${ }^{9}$ Cs-SnS- $1,{ }^{30}$ and $\mathrm{DABCOH}-\mathrm{SnS}-1,{ }^{31,32}$ which featured a microporous layered structure with $2 \mathrm{D}\left[\mathrm{Sn}_{3} \mathrm{~S}_{7}\right]_{n}^{2 n-}$ layers stacked in AA sequence along the $c$-axis, and alkylammonium as counter cations existing in the interlayers. The host-guest interactions consisted of anion-cation electrostatic forces and hydrogen bonding. The interlayer distances of $(\mathrm{baH})_{2} \mathrm{Sn}_{3} \mathrm{~S}_{7},(\mathrm{haH})_{2} \mathrm{Sn}_{3} \mathrm{~S}_{7}$ and $(\mathrm{oaH})_{2}{ }^{-}$ $\mathrm{Sn}_{3} \mathrm{~S}_{7}$ increased as the organic amine chain grew, which was estimated to be $7.26 \AA$, $15.41 \AA$ and $16.68 \AA$, respectively. Compared with the alkylammonium ion length, it was concluded that the interlayered alkylammonium ion adopted an all-trans interdigital configuration within the hybrid. These results indicated that the open inorganic framework of the $\left[\mathrm{Sn}_{3} \mathrm{~S}_{7}\right]_{n}{ }^{2 n-}$ layers could adjust their lattice parameters to adopt the various counter cations. The UV-Vis absorption spectra were used to determine the band gaps of $\mathrm{A}_{2} \mathrm{Sn}_{3} \mathrm{~S}_{7}$, which were approximately $2.95 \mathrm{eV}, 2.56 \mathrm{eV}$ and $2.45 \mathrm{eV}$ for $(\mathrm{baH})_{2} \mathrm{Sn}_{3} \mathrm{~S}_{7}$, (haH $)_{2} \mathrm{Sn}_{3} \mathrm{~S}_{7}$ and $(\mathrm{oaH})_{2} \mathrm{Sn}_{3} \mathrm{~S}_{7}$, respectively (Fig. 1b). This demonstrated that the hybrids could absorb the UV-Vis light effectively. Furthermore, the scanning electron microscopy (SEM) analyses provided visual evidence for the layered nature of the $\mathrm{A}_{2} \mathrm{Sn}_{3} \mathrm{~S}_{7}$ hybrid (Fig. 1c-e), in accordance with the results of XRD mentioned above.

Meanwhile, the elemental contents of C, H, N and Sn listed in Table S1 in ESI $\dagger$ were used to confirm the formula of these thiostannates. All element data were consistent with the value calculated from the formula $\mathrm{A}_{2} \mathrm{Sn}_{3} \mathrm{~S}_{7}$, which demonstrated (baH) $)_{2} \mathrm{Sn}_{3} \mathrm{~S}_{7}$, (haH $)_{2} \mathrm{Sn}_{3} \mathrm{~S}_{7}$ and $(\mathrm{oaH})_{2} \mathrm{Sn}_{3} \mathrm{~S}_{7}$ compounds were successfully synthesized, and the three compounds could be represented by $\mathrm{A}_{2} \mathrm{Sn}_{3} \mathrm{~S}_{7}(\mathrm{~A}=\mathrm{baH}$, haH, oaH $)$.

To verify the valence state of the $\mathrm{Sn}$ and $\mathrm{S}$ elements of the hybrids, high resolution X-ray photoelectron spectra (XPS) was performed to obtain the Sn $3 \mathrm{~d}$ and $\mathrm{S} 2 \mathrm{p}$ spectra, all the three hybrids exhibited the similar spectra and those of the $(\mathrm{baH})_{2}$ $\mathrm{Sn}_{3} \mathrm{~S}_{7}$ were shown in Fig. S1 ESI. $\dagger$ The evolution of $\mathrm{Sn} 3 \mathrm{~d}$ with two strong peaks was observed at 495.3 and $486.8 \mathrm{eV}$, which were attributed to $\mathrm{Sn} 3 \mathrm{~d}_{3 / 2}$ and $\mathrm{Sn} 3 \mathrm{~d}_{5 / 2}$, respectively. The highresolution $\mathrm{S} 2 \mathrm{p}$ core level analysis at binding energies of 162.5 and $161.5 \mathrm{eV}$ corresponded to $\mathrm{S} 2 \mathrm{p}_{1 / 2}$ and $\mathrm{S} 2 \mathrm{p}_{3 / 2}$. The binding energies (Table S2 in ESI $\dagger$ ) of the $\mathrm{A}_{2} \mathrm{Sn}_{3} \mathrm{~S}_{7}$ revealed that all the Sn species were present in the $4+$ oxidation state, while all the $\mathrm{S}$ species were present in the 2- state. Therefore, XPS analysis further supported the formula of $\mathrm{A}_{2} \mathrm{Sn}_{3} \mathrm{~S}_{7}$.

To test the thermal stability of $\mathrm{A}_{2} \mathrm{Sn}_{3} \mathrm{~S}_{7}(\mathrm{~A}=\mathrm{baH}, \mathrm{haH}, \mathrm{oaH})$, TGA analyses were carried out and depicted in Fig. S2 of ESI. $\dagger$
The thermogravimetric curve demonstrated that (baH $)_{2} \mathrm{Sn}_{3} \mathrm{~S}_{7}$ exhibited the best thermal stability, as it could totally maintain the integrity of structure and composition below $220{ }^{\circ} \mathrm{C}$, which was related to its excellent crystallinity. $(\mathrm{haH})_{2} \mathrm{Sn}_{3} \mathrm{~S}_{7}$ and (oaH $)_{2} \mathrm{Sn}_{3} \mathrm{~S}_{7}$ were almost stable below $100^{\circ} \mathrm{C}$ owing to their poor crystallinity, although their thermal stability could still satisfy the requirements of ion-exchangers and photocatalysts in conventional wastewater treatment.

\subsection{Kinetic and isotherm studies of ion exchange}

RhB was selected as a prototype for the kinetic and isotherm studies of ion exchange. The kinetics of RhB ion exchange at $298 \mathrm{~K}$ were studied. Fig. 2a shows that the RhB concentration decreased sharply within the first few minutes, then decreased slightly to near zero, which demonstrated that $\mathrm{A}_{2} \mathrm{Sn}_{3} \mathrm{~S}_{7}$ (A = baH, haH, oaH) could effectively adsorb RhB. Among the three thiostannates, (haH $)_{2} \mathrm{Sn}_{3} \mathrm{~S}_{7}$ exhibited the fastest adsorption rate while (baH) $)_{2} \mathrm{Sn}_{3} \mathrm{~S}_{7}$ possessed the slowest rate. Fig. $2 \mathrm{~b}$ shows the kinetic fitting curves of $\mathrm{A}_{2} \mathrm{Sn}_{3} \mathrm{~S}_{7}$ for RhB adsorption with initial concentrations of $20 \mathrm{mg} \mathrm{L}^{-1}$. The pseudo-second order kinetic model was used to fit the experiment data.

The equation is expressed as:

$$
\frac{t}{q_{t}}=\frac{1}{k_{2} q_{\mathrm{e}}^{2}}+\frac{1}{q_{\mathrm{e}}} t
$$

where $q_{t}\left(\mathrm{mg} \mathrm{g}^{-1}\right)$ is the adsorption capacity at time $t$ (min), while $q_{\mathrm{e}}\left(\mathrm{mg} \mathrm{g}^{-1}\right)$ is the amount adsorbed at equilibrium. $k_{2}$ is the kinetic rate constant $\left(\mathrm{g} \mathrm{mg}^{-1} \mathrm{~min}^{-1}\right)$. According to the linear fitting results, all the correlation coefficients $\left(R^{2}\right)$ exceeded 0.99, which implied that the $\mathrm{RhB}$ adsorption on $\mathrm{A}_{2} \mathrm{Sn}_{3} \mathrm{~S}_{7}$ could be perfectly fitted with the pseudo second-order kinetic model, and the rate-limiting step of the adsorption was chemical adsorptions. The mechanism of adsorption was more likely to be ion exchange. The calculated kinetics parameters are given in Table 1. The kinetic rate constants $k_{2}$ were $0.34 \times 10^{-3}, 3.19 \times 10^{-3}$, and $0.71 \times 10^{-3} \mathrm{~g} \mathrm{mg}^{-1} \mathrm{~min}^{-1}$ for $(\mathrm{baH})_{2} \mathrm{Sn}_{3} \mathrm{~S}_{7},(\mathrm{haH})_{2} \mathrm{Sn}_{3} \mathrm{~S}_{7}$, and $(\mathrm{oaH})_{2} \mathrm{Sn}_{3} \mathrm{~S}_{7}$, respectively, namely $k_{2}\left[(\mathrm{haH})_{2} \mathrm{Sn}_{3} \mathrm{~S}_{7}\right]>k_{2}$ $\left[(\mathrm{oaH})_{2} \mathrm{Sn}_{3} \mathrm{~S}_{7}\right]>k_{2}\left[(\mathrm{baH})_{2} \mathrm{Sn}_{3} \mathrm{~S}_{7}\right]$. This phenomenon could be attributed to the combined effect of interlayer distance and dispersion of $\mathrm{A}_{2} \mathrm{Sn}_{3} \mathrm{~S}_{7}$ in an aqueous solution. Although the expansion of interlayer distance would facilitate the ion exchange between RhB cation ions and alkylammonium ions, the longer chain length of the organic amine would enhance the affinity with organic RhB cation and weaken the dispersibility of
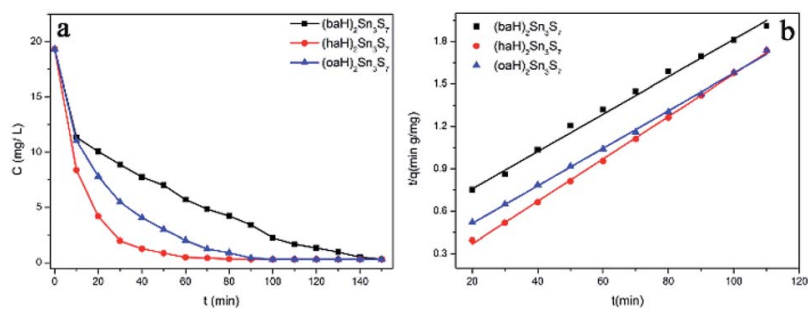

Fig. 2 Kinetics of RhB ion-exchange of $\mathrm{A}_{2} \mathrm{Sn}_{3} \mathrm{~S}_{7}$, RhB concentration C ( $\mathrm{mg} \mathrm{L}^{-1}$ ) vs. the time (min) (a); pseudo-second-order model for $\mathrm{A}_{2} \mathrm{Sn}_{3} \mathrm{~S}_{7}$ (b). 
Table 1 Adsorption kinetics parameters for $\mathrm{A}_{2} \mathrm{Sn}_{3} \mathrm{~S}_{7}$

\begin{tabular}{llll}
\hline & \multicolumn{3}{l}{ Pseudo-second-order } \\
\cline { 2 - 4 } & $\begin{array}{l}k_{2}\left(10^{-3} \mathrm{~g}\right. \\
\left.\mathrm{mg}^{-1} \mathrm{~min}^{-1}\right)\end{array}$ & $q_{\mathrm{e}}\left(\mathrm{mg} \mathrm{g}^{-1}\right)$ & $R^{2}$ \\
\hline$(\mathrm{baH})_{2} \mathrm{Sn}_{3} \mathrm{~S}_{7}$ & 0.34 & 76.33 & 0.9939 \\
$(\mathrm{haH})_{2} \mathrm{Sn}_{3} \mathrm{~S}_{7}$ & 3.19 & 66.67 & 0.9992 \\
$(\mathrm{oaH})_{2} \mathrm{Sn}_{3} \mathrm{~S}_{7}$ & 0.71 & 75.24 & 0.9989
\end{tabular}

$\mathrm{A}_{2} \mathrm{Sn}_{3} \mathrm{~S}_{7}$ in aqueous solution at the same time, consequently, retarding the integrated ion-exchange rate.

According to the results of the kinetic experiments, $\mathrm{A}_{2} \mathrm{Sn}_{3} \mathrm{~S}_{7}$ ( $\mathrm{A}=\mathrm{baH}, \mathrm{haH}, \mathrm{oaH}$ ) could adsorb RhB by an ion-exchange reaction. To evaluate the adsorption capacity of $\mathrm{A}_{2} \mathrm{Sn}_{3} \mathrm{~S}_{7}$, isotherm experiments with an initial concentration ranging from 20 to $450 \mathrm{mg} \mathrm{L}^{-1}$ of RhB solution in neutral conditions was carried out. However, we found that the adsorption rate reduced with the increase of concentration of RhB. In order to seek for the suitable adsorption temperature, $(\mathrm{haH})_{2} \mathrm{Sn}_{3} \mathrm{~S}_{7}$ was used to study the relationship between adsorption rate and temperature (Fig. 3). The results showed that the adsorption rate accelerated significantly at $333 \mathrm{~K}$, almost consistent with the effects at $348 \mathrm{~K}$ and $363 \mathrm{~K}$. Therefore, the final isothermal adsorption temperature was determined to be $333 \mathrm{~K}$. The Langmuir equilibrium equation is expressed as:

$$
q_{\mathrm{e}}=q_{\mathrm{m}} \frac{b C_{\mathrm{e}}}{1+b C_{\mathrm{e}}}
$$

where $q_{\mathrm{e}}\left(\mathrm{mg} \mathrm{g}^{-1}\right)$ is the adsorption capacity at equilibrium, $C_{\mathrm{e}}$ $\left(\mathrm{mg} \mathrm{L}^{-1}\right)$ is the equilibrium concentration; $q_{\mathrm{m}}\left(\mathrm{mg} \mathrm{g}^{-1}\right)$ is the maximum adsorption capacity, and $b\left(\mathrm{~L} \mathrm{mg}^{-1}\right)$ is the Langmuir affinity constant related to the binding strength. The equilibrium curve of RhB is shown in Fig. 4, which describes the capacity of RhB-exchange $\left(q_{\mathrm{e}}\right) v s$. the concentration of $\mathrm{RhB}\left(C_{\mathrm{e}}\right)$ at equilibrium. Nonlinear fitting indicated that the Langmuir isotherm model was appropriate to describe the adsorption behaviour of $\mathrm{A}_{2} \mathrm{Sn}_{3} \mathrm{~S}_{7}$ towards RhB with $R^{2}=0.9442,0.9854$ and

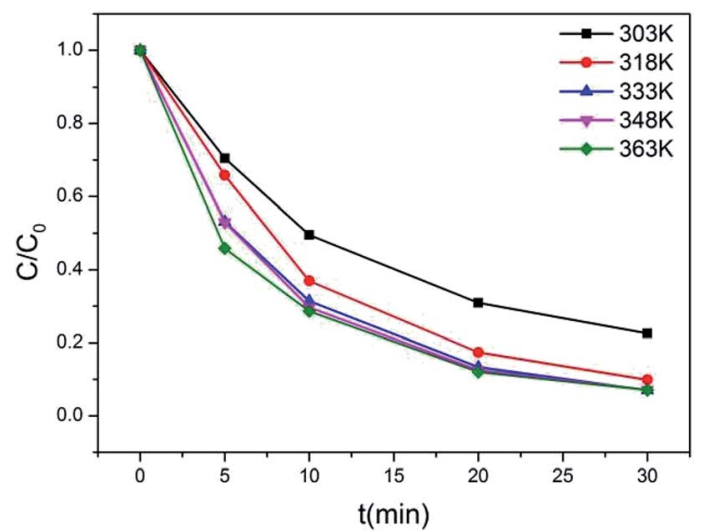

Fig. 3 Kinetics of RhB $\left(20 \mathrm{mg} \mathrm{L}^{-1}\right)$ ion-exchange of $(\mathrm{haH})_{2} \mathrm{Sn}_{3} \mathrm{~S}_{7}$ at different temperature.
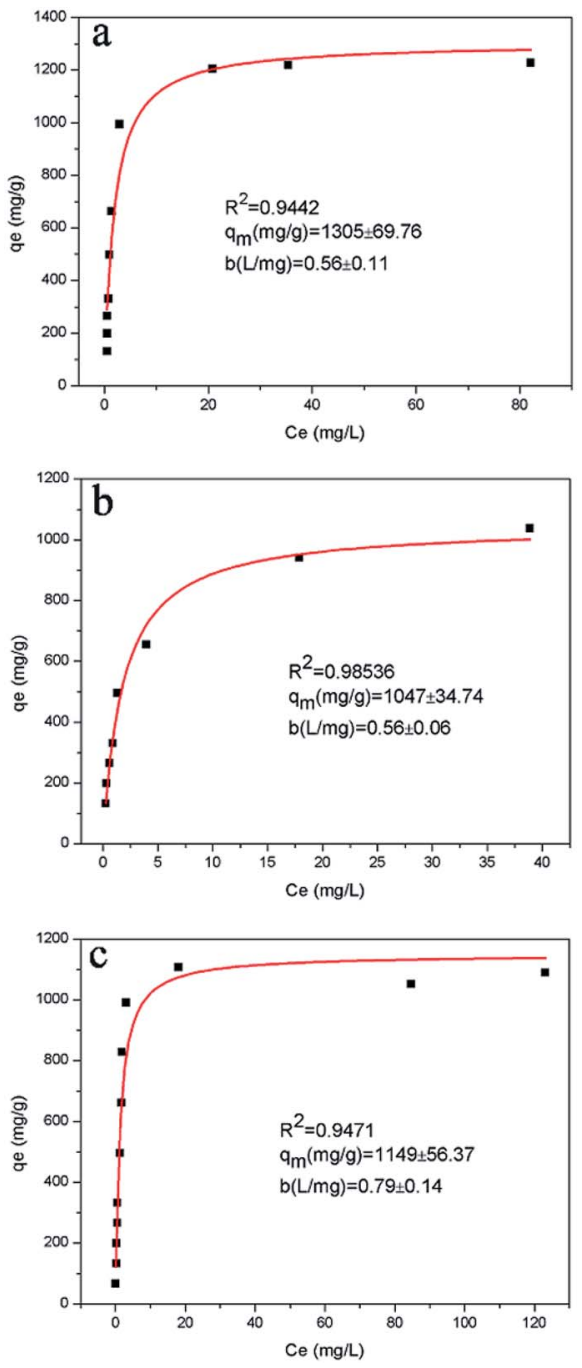

Fig. 4 RhB equilibrium curves for $\mathrm{A}_{2} \mathrm{Sn}_{3} \mathrm{~S}_{7}$ at $333 \mathrm{~K}$, Langmuir equilibrium isotherms $q_{e}$ vs. $C_{e}$ for $(b a H)_{2} \mathrm{Sn}_{3} \mathrm{~S}_{7}(\mathrm{a}),(\mathrm{haH})_{2} \mathrm{Sn}_{3} \mathrm{~S}_{7}$ (b), and $(\mathrm{oaH})_{2} \mathrm{Sn}_{3} \mathrm{~S}_{7}$ (c).

0.9471 corresponding to (baH) $)_{2} \mathrm{Sn}_{3} \mathrm{~S}_{7},(\mathrm{haH})_{2} \mathrm{Sn}_{3} \mathrm{~S}_{7}$ and (oaH) $)_{2}$ $\mathrm{Sn}_{3} \mathrm{~S}_{7}$, respectively. The Langmuir isotherm model is based on the assumptions that the adsorption surface is homogeneous and each site can capture only one ion, which is a monolayertype adsorption. The value of $q_{\mathrm{m}}$ was calculated to be $1305 \pm$ $69.76 \mathrm{mg} \mathrm{g}^{-1}, 1047 \pm 34.74 \mathrm{mg} \mathrm{g}^{-1}$ and $1149 \pm 56.37 \mathrm{mg} \mathrm{g}^{-1}$ for $(\mathrm{baH})_{2} \mathrm{Sn}_{3} \mathrm{~S}_{7},(\mathrm{haH})_{2} \mathrm{Sn}_{3} \mathrm{~S}_{7}$ and $(\mathrm{oaH})_{2} \mathrm{Sn}_{3} \mathrm{~S}_{7}$, respectively. The order of $q_{\mathrm{m}}$ values was in agreement with the trend of $q_{\mathrm{e}}$ in the kinetic experiments (76.33 for $(\mathrm{baH})_{2} \mathrm{Sn}_{3} \mathrm{~S}_{7}, 66.67$ for $(\mathrm{haH})_{2^{-}}$ $\mathrm{Sn}_{3} \mathrm{~S}_{7}$, and $75.24 \mathrm{mg} \mathrm{g}^{-1}$ for $\left.(\mathrm{oaH})_{2} \mathrm{Sn}_{3} \mathrm{~S}_{7}\right)$. Therefore, the adsorption capacity was also related to the active adsorption site of the ion-exchanger. In addition, to demonstrate the excellent adsorption performance of $\mathrm{A}_{2} \mathrm{Sn}_{3} \mathrm{~S}_{7}$, the maximal adsorption capacity towards $\mathrm{RhB}$ was compared with some common adsorbents (see Table S3 in ESI $†$ ). ${ }^{33-40}$ The comparative results revealed that the $\mathrm{A}_{2} \mathrm{Sn}_{3} \mathrm{~S}_{7}(\mathrm{~A}=\mathrm{baH}, \mathrm{haH}, \mathrm{oaH})$ exhibited a very high $\mathrm{RhB}$ ion-exchange capacity which was mainly attributed to the affinity of interlayered alkylammonium and the electrostatic 
interaction of $2 \mathrm{D}\left[\mathrm{Sn}_{3} \mathrm{~S}_{7}\right]_{n}{ }^{2 n-}$ layers with the organic $\mathrm{RhB}$ cation.

The $\mathrm{pH}$ resistance is another important evaluative parameter for a good adsorbent. In general, a material with $K_{\mathrm{d}}$ (distribution coefficient) greater than $10^{4} \mathrm{~mL} \mathrm{~g}^{-1}$ is regarded as an excellent adsorbent. Fig. 5 a shows the $K_{\mathrm{d}}$ of $\mathrm{A}_{2} \mathrm{Sn}_{3} \mathrm{~S}_{7}$ in a $\mathrm{RhB}$ solution with different $\mathrm{pH}$. Since the $K_{\mathrm{d}}$ value of $(\mathrm{haH})_{2} \mathrm{Sn}_{3} \mathrm{~S}_{7}$ in the solution of $\mathrm{pH} \approx 9$ and 11 were too large, we used a third of that value to plot. As shown in Fig. $5 \mathrm{a}$, the $K_{\mathrm{d}}$ value of $(\mathrm{baH})_{2^{-}}$ $\mathrm{Sn}_{3} \mathrm{~S}_{7}$ was determined as $4.0 \times 10^{5} \mathrm{~mL} \mathrm{~g}^{-1}$ when $\mathrm{pH} \approx 1$, then the value decreased with the increase of $\mathrm{pH}$ until $\mathrm{pH} \approx 9\left(K_{\mathrm{d}}=\right.$ $\left.1.32 \times 10^{4} \mathrm{~mL} \mathrm{~g}^{-1}\right)$. It was possible that in a strong alkaline solution, the electrostatic repulsive-force between $-\mathrm{COO}^{-}$of $\mathrm{RhB}$ and $2 \mathrm{D}\left[\mathrm{Sn}_{3} \mathrm{~S}_{7}\right]_{n}{ }^{2 n-}$ layers prevented the $\mathrm{RhB}$ cation from entering into the narrow amine layers of $(\mathrm{baH})_{2} \mathrm{Sn}_{3} \mathrm{~S}_{7}$. For $(\mathrm{haH})_{2} \mathrm{Sn}_{3} \mathrm{~S}_{7}$ and $(\mathrm{oaH})_{2} \mathrm{Sn}_{3} \mathrm{~S}_{7}$, the trend was reversed. In the solution with $\mathrm{pH} \approx 1$, the $K_{\mathrm{d}}$ were determined as $3.57 \times 10^{4} \mathrm{~mL}$ $\mathrm{g}^{-1}$ for $(\mathrm{haH})_{2} \mathrm{Sn}_{3} \mathrm{~S}_{7}$ and $2.89 \times 10^{3} \mathrm{~mL} \mathrm{~g}^{-1}$ for $(\mathrm{oaH})_{2} \mathrm{Sn}_{3} \mathrm{~S}_{7}$, owing to the high concentration of $\mathrm{H}^{+}$as the competitive ions. With the increase of $\mathrm{pH}$, both adsorbents displayed outstanding adsorption capability. Especially when $\mathrm{pH} \approx 9$, the $K_{\mathrm{d}}$ reached a maximum of $3.57 \times 10^{6}$, and $1.01 \times 10^{5} \mathrm{~mL} \mathrm{~g}^{-1}$, owing to the decrease of the $\mathrm{H}^{+}$concentration, then when the $\mathrm{pH}$ reached 11, the $K_{\mathrm{d}}$ slightly decreased to $1.02 \times 10^{5}$ and $7.19 \times 10^{4} \mathrm{~mL} \mathrm{~g}^{-1}$ for $(\mathrm{haH})_{2} \mathrm{Sn}_{3} \mathrm{~S}_{7}$ and $(\mathrm{oaH})_{2} \mathrm{Sn}_{3} \mathrm{~S}_{7}$, respectively, owing to the partial structure destruction. Therefore, the $\mathrm{pH}$ resistance data demonstrated that $\mathrm{A}_{2} \mathrm{Sn}_{3} \mathrm{~S}_{7}(\mathrm{~A}=\mathrm{baH}, \mathrm{haH}, \mathrm{oaH})$ was a good
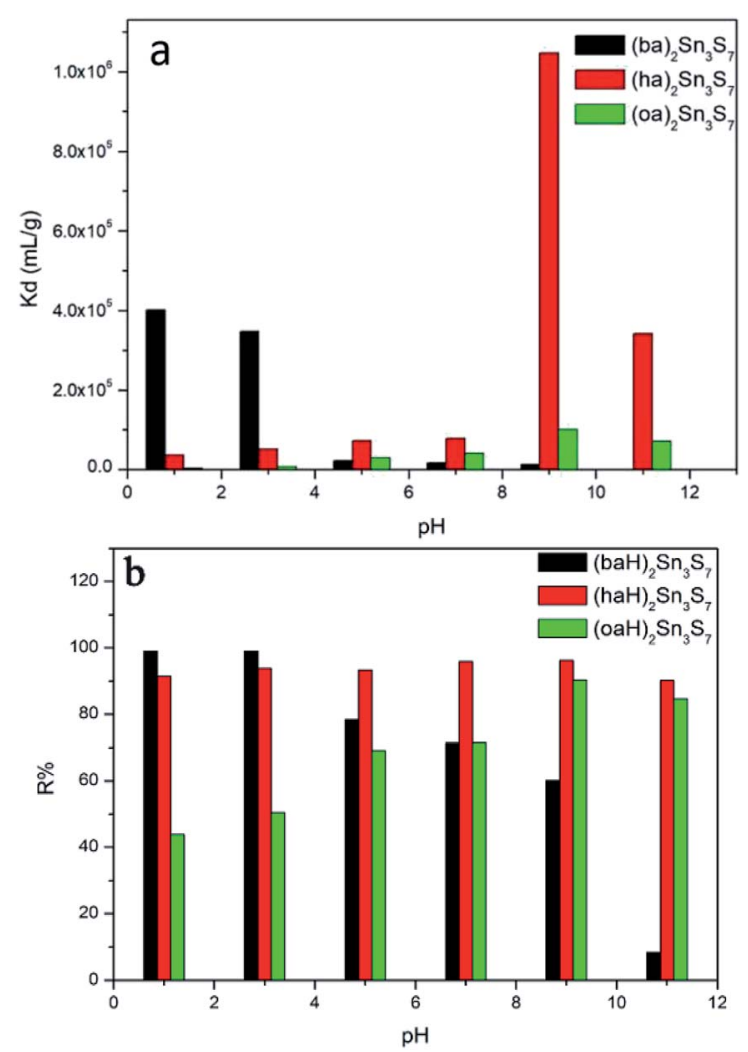

Fig. $5 \quad K_{d}$ of $\mathrm{A}_{2} \mathrm{Sn}_{3} \mathrm{~S}_{7}$ in $\mathrm{RhB}$ solution (a) and removal rates $R \%$ of $\mathrm{RhB}$ (b) at different $\mathrm{pH}$. adsorbent over a wide $\mathrm{pH}$ solution range $(\mathrm{pH}=1-11)$. Meanwhile, the RhB removal efficiency $(R \%) v s$. $\mathrm{pH}$ was shown in Fig. $5 \mathrm{~b}$, which further illustrated that $(\mathrm{baH})_{2} \mathrm{Sn}_{3} \mathrm{~S}_{7}$ was more suitable to remove $\mathrm{RhB}$ in acidic conditions, while (oaH $)_{2} \mathrm{Sn}_{3} \mathrm{~S}_{7}$ preferred to eradicate $\mathrm{RhB}$ in basic conditions and the hybrids were structural stable and maintained an excellent ionexchange performance over a wide $\mathrm{pH}$ range (Fig. S3 in ESI†).

\subsection{Photocatalytic activities}

In addition to the high capacity and wide $\mathrm{pH}$ resistance of $\mathrm{A}_{2} \mathrm{Sn}_{3} \mathrm{~S}_{7}$, the photocatalytic ability to degrade organic $\mathrm{RhB}$ cation is discussed. All the photocatalytic experiments were carried out at $298 \mathrm{~K}$ in a $250 \mathrm{~mL}$ quartz reactor. RhB solutions (100 mL; $20 \mathrm{mg} \mathrm{L}^{-1}$ ) containing the $\mathrm{A}_{2} \mathrm{Sn}_{3} \mathrm{~S}_{7}$ sample $(30 \mathrm{mg}$ ) were magnetically stirred in the dark to reach the adsorptiondesorption equilibrium, then irradiated by a $300 \mathrm{~W}$ Xenon lamp $(\lambda>420 \mathrm{~nm})$. During the kinetic experiments, the UV-Vis spectrophotometer failed to detect the concentration variation of $\mathrm{RhB}$ in the aqueous solution because $\mathrm{RhB}$ had been strongly adsorbed between the amine layers of $\mathrm{A}_{2} \mathrm{Sn}_{3} \mathrm{~S}_{7}$.

To detect the RhB concentration at different reaction time, we adopted a new method, called dispersive liquid-liquid microextraction (DLLME). ${ }^{41,42}$ To be more specific, the mixture extraction agent consisting of absolute ethyl alcohol and dichloromethane were used to extract the adsorbed but undegraded $\mathrm{RhB}$ in the interlayers. The extraction process was repeated for twice to guarantee the complete collection of undegraded RhB molecules, detected by the fluorescence of the extraction solution (Fig. S4 in ESI†). The fluorescence spectra were obtained, with excitation wavelength at $294 \mathrm{~nm}$ and both excitation and emission slit widths set to $3 \mathrm{~nm}$, to capture the emission band intensity of $\mathrm{RhB}$ during the photocatalytic process. The change of fluorescence intensity at $570 \mathrm{~nm}$ made it possible to determine a variation of the concentration of RhB. Fig. 6a-c shows the fluorescence spectra change of RhB in the
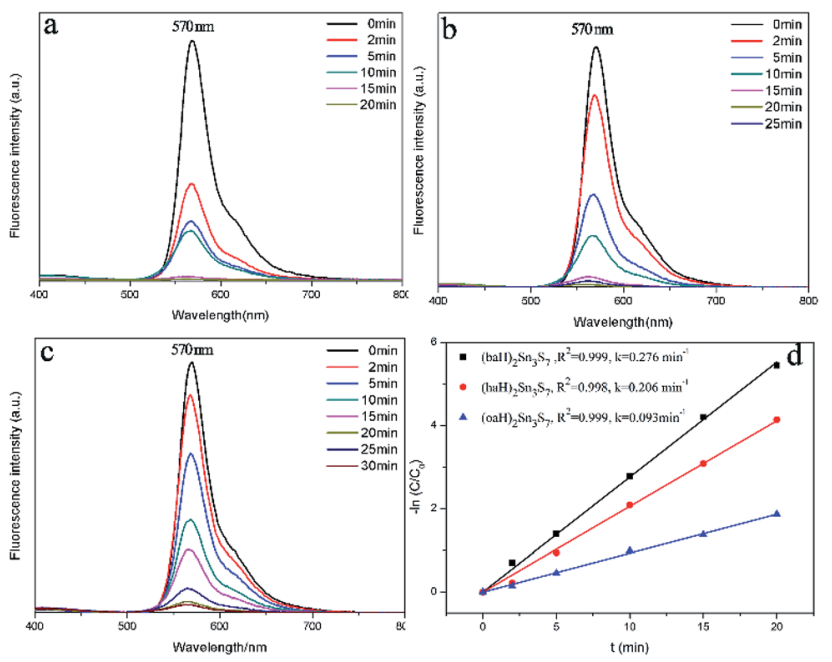

Fig. 6 (a) (baH) $)_{2} \mathrm{Sn}_{3} \mathrm{~S}_{7}$, (b) $(\mathrm{haH})_{2} \mathrm{Sn}_{3} \mathrm{~S}_{7}$, (c) $(\mathrm{oaH})_{2} \mathrm{Sn}_{3} \mathrm{~S}_{7}$ fluorescence spectral changes of the RhB extracting solution; (d) pseudo-first-order model for $\mathrm{A}_{2} \mathrm{Sn}_{3} \mathrm{~S}_{7}$ in the photocatalytic process. 
extracting solution. From the fluorescence spectra, $(\mathrm{baH})_{2} \mathrm{Sn}_{3} \mathrm{~S}_{7}$ was able to thoroughly degrade RhB within $15 \mathrm{~min},(\mathrm{haH})_{2} \mathrm{Sn}_{3} \mathrm{~S}_{7}$ needed $20 \mathrm{~min}$ and $(\mathrm{oaH})_{2} \mathrm{Sn}_{3} \mathrm{~S}_{7}$ needed approximately $30 \mathrm{~min}$ to remove $\mathrm{RhB}$ by a photocatalytic reaction. The LangmuirHinshelwood (L-H) apparent first-order kinetics model was adopted to describe the photocatalytic ability of $\mathrm{A}_{2} \mathrm{Sn}_{3} \mathrm{~S}_{7}$. The $\mathrm{L}-\mathrm{H}$ equation is described as follows:

$$
r=\frac{\mathrm{d} C}{\mathrm{~d} t}=\frac{k K C}{(1+K C)}
$$

where $r$ is the degradation rate of the reactant $\left(\mathrm{mg} \mathrm{L}^{-1} \mathrm{~min}^{-1}\right), C$ is the concentration of the reactant $\left(\mathrm{mg} \mathrm{L}^{-1}\right), t$ is the visible light irradiation time $(\mathrm{min}), k$ is the reaction rate constant $(\mathrm{mg}$ $\left.\mathrm{L}^{-1} \min ^{-1}\right)$, and $K$ is the adsorption coefficient of the reactant $(\mathrm{L}$ $\left.\mathrm{mg}^{-1}\right)$. When the initial concentration $\left(C_{0}\right)$ is very low $\left(C_{0}=\right.$ $20 \mathrm{mg} \mathrm{L}^{-1}$ for RhB in the present experiments), eqn (3) could be simplified to an apparent first-order model:

$$
\ln \frac{C_{0}}{C}=k K t=k_{\text {app }} t
$$

where $k_{\text {app }}$ is the apparent first-order rate constant $\left(\mathrm{min}^{-1}\right)$. Fig. $6 \mathrm{~d}$ shows that a linear relation between $\ln \left(C_{0} / C\right)$ and time was observed for all the photocatalysts, which indicated that the photocatalytic degradation of RhB was well fitted to pseudofirst-order kinetics, and the apparent rate $k_{\text {app }}$ was $0.276 \mathrm{~min}^{-1}$ for $(\mathrm{baH})_{2} \mathrm{Sn}_{3} \mathrm{~S}_{7}, 0.206 \mathrm{~min}^{-1}$ for $(\mathrm{haH})_{2} \mathrm{Sn}_{3} \mathrm{~S}_{7}$, and $0.093 \mathrm{~min}^{-1}$ for $(\mathrm{oaH})_{2} \mathrm{Sn}_{3} \mathrm{~S}_{7}$. The results revealed that $\mathrm{RhB}$ could be thoroughly degraded by an $\mathrm{A}_{2} \mathrm{Sn}_{3} \mathrm{~S}_{7}(\mathrm{~A}=\mathrm{baH}, \mathrm{haH}$, $\mathrm{oaH}$ ) photocatalyst in a short period of time. In addition to the high adsorption capacity, which provided the continuous supply of target pollutants, the semiconductor property of the $2 \mathrm{D}\left[\mathrm{Sn}_{3} \mathrm{~S}_{7}\right]_{n}{ }^{2 n-}$ layers could respond to visual light and produce a separated photogenerated electron and hole to degrade the organic contaminant. Essentially, the high-performance integrated adsorption-photodegradation ability was ascribed to the unique hybrid structure of $\mathrm{A}_{2} \mathrm{Sn}_{3} \mathrm{~S}_{7}$.

To test the stability and reusability of $\mathrm{A}_{2} \mathrm{Sn}_{3} \mathrm{~S}_{7},(\mathrm{baH})_{2} \mathrm{Sn}_{3} \mathrm{~S}_{7}$ was reused four times for the photocatalytic reaction under the same conditions. The results are shown in Fig. 7. There was no significant decrease in the photocatalytic activity of $(\mathrm{baH})_{2} \mathrm{Sn}_{3} \mathrm{~S}_{7}$

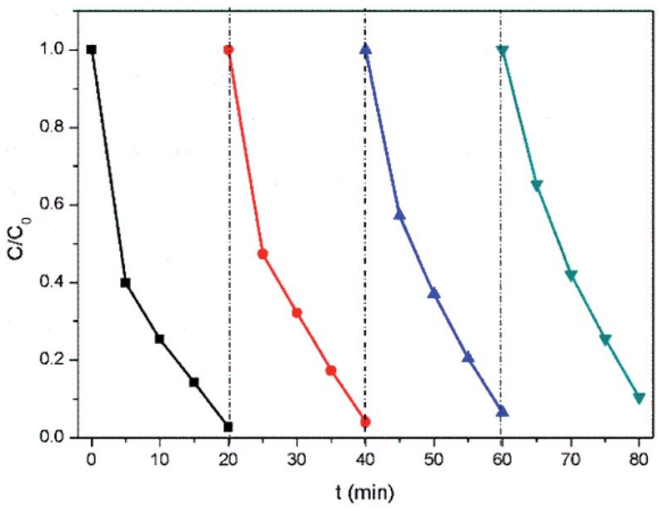

Fig. 7 Recycling test of $(\mathrm{baH})_{2} \mathrm{Sn}_{3} \mathrm{~S}_{7}$ in photocatalytic degradation of RhB. after the four consecutive photocatalytic degradation cycles, which indicated that ( $\mathrm{baH})_{2} \mathrm{Sn}_{3} \mathrm{~S}_{7}$ was stable and could be used repeatedly. Moreover, the XRD demonstrated that the structure of $(\mathrm{baH})_{2} \mathrm{Sn}_{3} \mathrm{~S}_{7}$ after four consecutive cycles was consistent with the original structure (Fig. S5 in ESI $\dagger$ ). The colored photos of $(\mathrm{baH})_{2} \mathrm{Sn}_{3} \mathrm{~S}_{7}$ powder undergo ion exchange, photocatalysis and elution in a cycle experiment were shown in Fig. S6 in ESI. $\dagger$ Thus, (baH) $)_{2} \mathrm{Sn}_{3} \mathrm{~S}_{7}$ showed remarkable stability and reproducibility for photocatalysis.

In a real sewage treatment process, the effects of adsorption and photocatalysis synergistically occur. To test the overall performance of $\mathrm{A}_{2} \mathrm{Sn}_{3} \mathrm{~S}_{7}$, integrated adsorption-photocatalysis experiments were conducted. In fact, the $\mathrm{RhB}$ degradation efficiency in the integrated experiment is actually determined by the adsorption efficiency and photocatalytic efficiency of $\mathrm{A}_{2} \mathrm{Sn}_{3} \mathrm{~S}_{7}$. If the adsorption capacity can meet the demand of photocatalytic degradation, the degradation efficiency will be
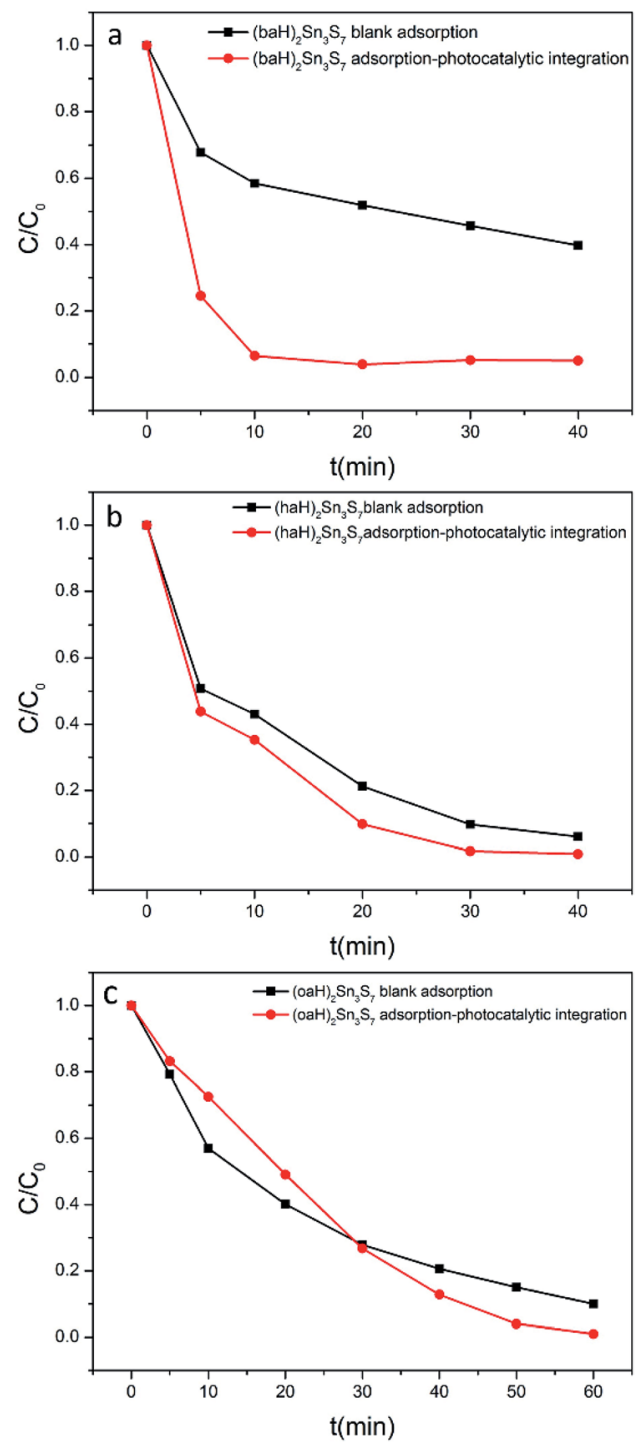

Fig. 8 Kinetics of RhB in dark environment and integrated adsorption-photocatalysis experiments. 


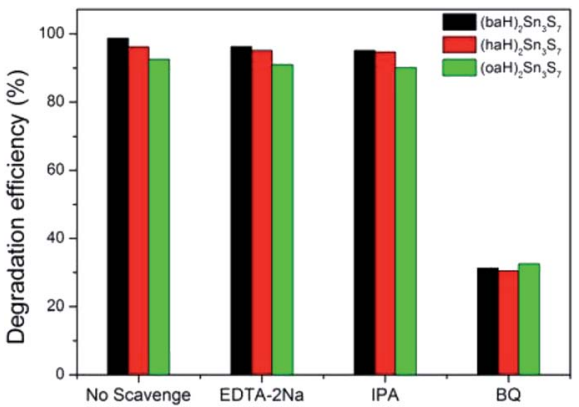

Fig. 9 Photocatalytic activities of the $\mathrm{A}_{2} \mathrm{Sn}_{3} \mathrm{~S}_{7}$ for the degradation of $\mathrm{RhB}$ solution in the presence of different trapping agents.

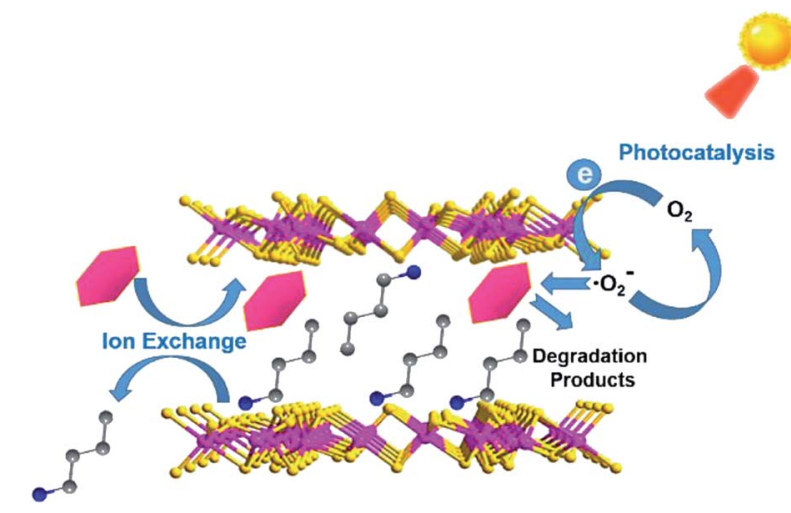

Scheme 1 Possible photocatalytic mechanism in $\mathrm{A}_{2} \mathrm{Sn}_{3} \mathrm{~S}_{7}$.

greatly improved (Fig. 8). In a dark environment, the time for the total adsorption of $\mathrm{RhB}$ was $150 \mathrm{~min}, 60 \mathrm{~min}$ and $90 \mathrm{~min}$ when using (baH) $)_{2} \mathrm{Sn}_{3} \mathrm{~S}_{7}$, (haH $)_{2} \mathrm{Sn}_{3} \mathrm{~S}_{7}$ and $(\mathrm{oaH})_{2} \mathrm{Sn}_{3} \mathrm{~S}_{7}$ as adsorbents, respectively (Fig. S7 in ESI $\uparrow$ ). However, in the integrated adsorption-photocatalysis experiments, the time for $\mathrm{RhB}$ to be thoroughly degraded was $15 \mathrm{~min}, 30 \mathrm{~min}$ and $60 \mathrm{~min}$ for $(\mathrm{baH})_{2} \mathrm{Sn}_{3} \mathrm{~S}_{7},(\mathrm{haH})_{2} \mathrm{Sn}_{3} \mathrm{~S}_{7}$ and $(\mathrm{oaH})_{2} \mathrm{Sn}_{3} \mathrm{~S}_{7}$, respectively. While, if the adsorption amount is insufficient, the degradation efficiency will decrease in a short time. Exactly as $(\mathrm{oaH})_{2} \mathrm{Sn}_{3} \mathrm{~S}_{7}$, in the first $30 \mathrm{~min}$, the degradation efficiency was slower owning to the poor adsorption. This definitely demonstrated that the degradation of RhB could be accelerated when adsorption and photocatalysis occurred synergistically, which indicated that $\mathrm{A}_{2} \mathrm{Sn}_{3} \mathrm{~S}_{7}$ photocatalysts with remarkable adsorbability could realize a rapid photocatalytic degradation of RhB under visible light.

\subsection{Photocatalytic mechanism}

According to the UV-visible spectra of these hybrids, it can be found that the absorption edge was in the order of $(\mathrm{baH})_{2} \mathrm{Sn}_{3} \mathrm{~S}_{7}$ $(2.95 \mathrm{eV}, 420 \mathrm{~nm})>(\mathrm{haH})_{2} \mathrm{Sn}_{3} \mathrm{~S}_{7}(2.56 \mathrm{eV}, 484 \mathrm{~nm})>(\mathrm{oaH})_{2} \mathrm{Sn}_{3} \mathrm{~S}_{7}$ $(2.45 \mathrm{eV}, 506 \mathrm{~nm})$. It is very possible that this order was related with the interaction between adjacent $\left[\mathrm{Sn}_{3} \mathrm{~S}_{7}{ }^{2-}\right]$ layers with their different spacing, given the identical intralayer structure of the $\left[\mathrm{Sn}_{3} \mathrm{~S}_{7}{ }^{2-}\right]$ layers. Upon the visible light illumination $(>420 \mathrm{~nm})$, the photodegradation rate sequence for Rhodamine B is same like the above order (Fig. 8), although the adsorption rate followed the different order, which indicates that the band edge excitons within the (baH) $)_{2} \mathrm{Sn}_{3} \mathrm{~S}_{7}$ is more efficient for the photodegradation reaction, compared with that hot excitons in the $(\mathrm{haH})_{2} \mathrm{Sn}_{3} \mathrm{~S}_{7}$ and $(\mathrm{oaH})_{2} \mathrm{Sn}_{3} \mathrm{~S}_{7}$. Of course, more depth investigation should be carried out to reveal the details of the relation between the light absorption, exciton energy and the photodegradation performance of these hybrids. This feature was also an implication of the independence between the adsorption and photodegradation process for this unique inorganic/ organic hybrid.

To investigate the mechanism of the photocatalytic process, the trapping experiments of the main active species $\mathrm{h}^{+}, \cdot \mathrm{OH}$, and $\cdot \mathrm{O}_{2}^{-}$radicals were designed by adding $1.0 \mathrm{mmol} \mathrm{L}^{-1}$ EDTA (a quencher of holes), $1.0 \mathrm{mmol} \mathrm{L}^{-1}$ IPA (a quencher of $\cdot \mathrm{OH}$ ) and $1.0 \mathrm{mmol} \mathrm{L}{ }^{-1} \mathrm{BQ}$ (a quencher of $\cdot \mathrm{O}_{2}^{-}$), respectively, into the system.

The degradation activity was slightly changed in the presence of EDTA or IPA, which indicated that $\mathrm{h}^{+}$and $\cdot \mathrm{OH}$ had a negligible effect on the photodegradation of RhB. However, when $\mathrm{BQ}$ was added, the degradation efficiency sharply reduced, which meant the photocatalytic process was restrained ${ }^{43}$ (Fig. 9). Therefore, the $\cdot \mathrm{O}_{2}{ }^{-}$radicals were the decisive active species in the degradation of $\mathrm{RhB}$, and the degradation mechanism of $\mathrm{A}_{2} \mathrm{Sn}_{3} \mathrm{~S}_{7}$ could be concluded as follows:

$$
\begin{gathered}
0\left(\mathrm{~A}_{2} \mathrm{Sn}_{3} \mathrm{~S}_{7}\right)-h \nu \rightarrow \mathrm{h}^{+}\left(\mathrm{S}^{-}\right)+\mathrm{e}^{-}\left(\mathrm{Sn}^{3+}\right) \\
\mathrm{O}_{2}+\mathrm{e}^{-} \rightarrow \cdot \mathrm{O}_{2}^{-} \\
\cdot \mathrm{O}_{2}^{-}+\mathrm{RhB}^{+} \rightarrow \text { degradation products }
\end{gathered}
$$

Thus, there was a possible photocatalytic mechanism proposed according to the aforementioned experimental results and this is summarized and shown in Scheme 1. The reason why $\mathrm{A}_{2} \mathrm{Sn}_{3} \mathrm{~S}_{7}(\mathrm{~A}=\mathrm{baH}, \mathrm{haH}, \mathrm{oaH})$ could realize a rapid photodegradation of $\mathrm{RhB}$ was attributed to their unique layered structures. RhB could exchange with interlayered alkylammonium to realize its rapid accumulation within the interlayers of the hybrid. Furthermore, under illumination, photogenerated electrons from the $\left(\mathrm{Sn}_{3} \mathrm{~S}_{7}\right)_{n}{ }^{2 n-}$ anion layers could be quickly captured by dissolved oxygen to produce $\cdot \mathrm{O}_{2}{ }^{-}$radical, which could then attack adjacent adsorbed RhB molecules within the nanometer scale. Finally, the carcinogenic and nonbiodegradable organic dye RhB was thoroughly photodegraded. This hybrid outperformed traditional photocatalysts with decoupled adsorption and photocatalytic properties, and can be used as an adsorbent in the dark and as a photocatalyst in daylight, which is well compatible for the intermittent feature of solar light.

\section{Conclusions}

In conclusion, a series of layered thiostannates $\mathrm{A}_{2} \mathrm{Sn}_{3} \mathrm{~S}_{7}(\mathrm{~A}=$ baH, haH, oaH), with integrated high adsorption and fast photocatalysis, could be synthesized by a facile, one-pot 
solvothermal method. The structure of layered $\mathrm{A}_{2} \mathrm{Sn}_{3} \mathrm{~S}_{7}(\mathrm{~A}=$ baH, haH, oaH) was characterized by the periodic arrangement of $2 \mathrm{D}\left[\mathrm{Sn}_{3} \mathrm{~S}_{7}\right]_{n}{ }^{2 n-}$ layers and interlayered alkylammonium. Based on the unique hybrid structure, $\mathrm{A}_{2} \mathrm{Sn}_{3} \mathrm{~S}_{7}(\mathrm{~A}=\mathrm{baH}, \mathrm{haH}$, $\mathrm{oaH}$ ) would be able to efficiently degrade organic cationic pollutants in sewage water, like RhB. The ion-exchange studies targeted at $\mathrm{RhB}$ revealed that $\mathrm{A}_{2} \mathrm{Sn}_{3} \mathrm{~S}_{7}$ exhibited a remarkable ion-exchange capacity and wide $\mathrm{pH}$ resistance. The photocatalytic experiments demonstrated that $\mathrm{A}_{2} \mathrm{Sn}_{3} \mathrm{~S}_{7}$ exhibited excellent photocatalytic activity and reusability. For conventional photocatalysts, the effect of photocatalysis is more decisive than adsorption, which means that these photocatalysts are only available in the daytime. However, the novel $\mathrm{A}_{2} \mathrm{Sn}_{3} \mathrm{~S}_{7}(\mathrm{~A}=$ baH, haH, oaH) photocatalysts synthesized in this paper can decouple the adsorption from photocatalysis to realize their independent functions. During the day, $\mathrm{A}_{2} \mathrm{Sn}_{3} \mathrm{~S}_{7}(\mathrm{~A}=\mathrm{baH}, \mathrm{haH}$, $\mathrm{oaH})$ acts as photocatalyst to rapidly and thoroughly degrade organic pollutants, and at night, it can serve as a superior ionexchanger to adsorb contaminants to prepare for the next photocatalysis cycle. It is expected that these multifunctional $\mathrm{A}_{2} \mathrm{Sn}_{3} \mathrm{~S}_{7}$ materials could be developed to deal with larger organic cationic pollutants, like dyes and pigments. More research is needed to degrade other nonbiodegradable organic contaminants. These hybrids outperform traditional photocatalysts with decoupled adsorption and photocatalytic properties, and can be used as adsorbents in the dark and as photocatalysts in daylight, which makes them compatible with the intermittent nature of solar light.

\section{Conflicts of interest}

There are no conflicts to declare.

\section{Acknowledgements}

We thank Liwen Bianji, Edanz Group China (www.liwenbianji.cn/ac), for editing the English text of a draft of this manuscript.

\section{Notes and references}

1 K. Y. Wang, M. L. Feng, L. J. Zhou, J. R. Li, X. H. Qi and X. Y. Huang, Chem. Commun., 2014, 50, 14960-14963.

2 X. Y. Huang and J. Li, J. Am. Chem. Soc., 2000, 122, 87898790.

3 Y. F. Sun, Z. H. Sun, S. Gao, H. Cheng, Q. H. Liu, J. Y. Piao, T. Yao, C. Z. Wu, S. L. Hu, S. Q. Wei and Y. Xie, Nat. Commun., 2012, 3, 1057.

4 J. F. Xie, S. Li, R. X. Wang, H. Zhang and Y. Xie, Chem. Sci., 2014, 5, 1328-1335.

5 R. L. Bedard, S. T. Wilson, L. D. Vail, J. M. Bennett and E. M. Flanigen, in Zeolites: Facts, Figures, Future, Proceedings of the 8th International Zeolite Conference, ed. P. A. Jacobs and R. A. van Santen, Elsevier, Amsterdam, 1989, pp. 375-387.

6 W. S. Sheldrick and M. Wachhold, Coord. Chem. Rev., 1998, 176, 211-322.
7 T. Jiang, A. Lough, G. A. Ozin, R. L. Bedard and R. Broach, J. Mater. Chem., 1998, 8, 721-732.

8 T. Jiang, A. Lough, G. A. Ozin and R. L. Bedard, J. Mater. Chem., 1998, 8, 733-741.

9 X. H. Qi, K. Z. Du, M. L. Feng, J. R. Li, C. F. Du, B. Zhang and X. Y. Huang, J. Mater. Chem. A, 2015, 3, 5665-5673.

10 M. L. Feng, D. Sarma, X. H. Qi, K. Z. Du, X. Y. Huang and M. G. Kanatzidis, J. Am. Chem. Soc., 2016, 138, 12578-12585.

11 X. H. Qi, K. Z. Du, M. L. Feng, Y. J. Gao, X. Y. Huang and M. G. Kanatzidis, J. Am. Chem. Soc., 2017, 139, 4314-4317.

12 M. L. Feng, K. Y. Wang and X. Y. Huang, Chem. Rec., 2016, 16, 582-600.

13 N. Ding and M. G. Kanatzidis, Chem. Mater., 2007, 19, 38673869.

14 N. Ding and M. G. Kanatzidis, Nat. Chem., 2010, 2, 187-191. 15 M. L. Feng, D. N. Kong, Z. L. Xie and X. Y. Huang, Angew. Chem., Int. Ed. Engl., 2008, 47, 8623-8626.

16 J. R. Li and X. Y. Huang, Dalton Trans., 2011, 40, 4387-4390. 17 J. L. Mertz, Z. H. Fard, C. D. Malliakas, M. J. Manos and M. G. Kanatzidis, Chem. Mater., 2013, 25, 2116-2127.

18 M. J. Manos, C. D. Malliakas and M. G. Kanatzidis, Chem.Eur. J., 2007, 13, 51-58.

19 P. Sengupta, N. L. Dudwadkar, B. Vishwanadh, V. Pulhani, R. Rao, S. C. Tripathi and G. K. Dey, J. Hazard. Mater., 2014, 266, 94-101.

20 T. Y. Zhai, X. S. Fang, L. Li, Y. Bando and D. Golberg, Nanoscale, 2010, 2, 168-187.

21 G. W. Li, R. Su, J. C. Rao, J. Q. Wu, P. Rudolf, G. R. Blake, R. A. deGroot, F. Besenbacher and T. T. M. Palstra, J. Mater. Chem. A, 2016, 4, 209-216.

22 L. L. Long, A. Y. Zhang, Y. X. Huang, X. Zhang and H. Q. Yu, J. Mater. Chem. A, 2015, 3, 4301-4306.

23 W. J. Zhou, Z. Y. Yin, Y. P. Du, X. Huang, Z. Y. Zeng, Z. X. Fan, H. Liu, J. Y. Wang and H. Zhang, Small, 2013, 9, 140-147.

24 L. Su, X. J. Ye, S. G. Meng, X. L. Fu and S. F. Chen, Appl. Surf. Sci., 2016, 384, 161-174.

25 Y. M. Xu and C. H. Langford, J. Phys. Chem., 1995, 99, 1150111507.

26 T. Torimoto, S. Ito and S. Yoneyama, Environ. Sci. Technol., 1996, 30, 1275-1281.

27 M. Takeuchi, T. Kimura, M. Hidaka, D. Rakhmawaty and M. Anpo, J. Catal., 2007, 246, 235-240.

28 U. I. Gaya and A. H. Abdullah, J. Photochem. Photobiol., C, 2008, 9, 1-12.

29 M. S. Hvid, P. Lamagni and N. Lock, Sci. Rep., 2017, 7, 45822.

30 G. A. Marking and M. G. Kanatzidis, J. Mater. Chem., 1995, 7, 1915-1921.

31 T. Jiang, A. Lough, G. A. Ozin and R. L. Bedard, J. Mater. Chem., 1998, 8, 733-741.

32 T. Jiang, A. Lough, G. A. Ozin, R. L. Bedard and R. Broach, J. Mater. Chem., 1998, 8, 721-732.

33 C. Yang, S. C. Wu, J. H. Cheng and Y. C. Chen, J. Alloys Compd., 2016, 687, 804-812.

34 K. Han, W. Wei, Z. F. Jiang, J. W. Lu, J. J. Zhu and J. M. Xie, Colloids Surf., A, 2016, 509, 539-549.

35 T. Bhowmik, M. K. Kundu and S. Barman, RSC Adv., 2015, 5, 38760-38773. 
36 J. N. Tiwari, K. Mahesh, N. H. Le, K. C. Kemp, R. Timilsina, R. N. Tiwari and K. S. Kim, Carbon, 2013, 56, 173-182.

37 X. J. Bian, X. F. Lu, Y. P. Xue, C. C. Zhang, L. R. Kong and C. Wang, J. Colloid Interface Sci., 2013, 406, 37-43.

38 S. Y. Wang, B. Yang and Y. P. Liu, J. Colloid Interface Sci., 2017, 507, 225-233.

39 X. H. Wang, J. J. Ding, S. W. Yao, X. X. Wu, Q. Q. Feng, Z. H. Wang and B. Y. Geng, J. Mater. Chem. A, 2014, 2, 15958-15963.
40 X. Q. Gao, F. Xiao, C. Yang, J. D. Wang and X. T. Su, J. Mater. Chem. A, 2013, 1, 5831-5834.

41 M. Rezaee, Y. Assadi, M. R. Milani Hosseini, E. Aghaee, F. Ahmadi and S. Berijani, J. Chromatogr. A, 2006, 1116, 1-9.

42 N. Xiao, J. Deng, K. H. Huang, S. Q. Ju, C. H. Hu and J. Liang, Spectrochim. Acta, Part A, 2014, 128, 312-318.

43 J. M. Wu and T. W. Zhang, J. Photochem. Photobiol., A, 2004, 162, 171-177. 